\title{
Research on Influence Factors of Enterprise M\&A Payment Mode Selection
}

\author{
Qiuheng TAN \\ Guosen Securities Co., Ltd. Shenzhen, 518001, China \\ tanqiuhengtqh@sina.com
}

Keywords: Enterprise M\&A; Payment mode; Influence factors

\begin{abstract}
Capital market becomes more and more mature, and M\&A is booming in Chinese market with development of economy in China, deepening of economic system reform, and comprehensive implementation of equity division reform. Single payment mode of M\&A can no longer meet the needs of enterprises with enlargement of enterprise merger and acquisition scale in China. Enterprise M\&A can play an important role in enterprise long-term development. Enterprise M\&A can expand the scale, form competitive advantage, improve the market share, and integrate resource. M\&A payment plays an important role in enterprise M\&A. Therefore, influence factors of enterprise M\&A payment mode selection are studied, main payment mode of enterprise M\&A and influence factors of M\&A payment mode selection mainly analyzed. In the paper, it is believed that M\&A enterprises should combine with actual situation, and fully consider influence factors of many aspects based on enterprise actual condition, thereby selecting the best payment mode.
\end{abstract}

\section{Introduction}

More and more enterprises like to select the development modes of merger, acquisition and reorganization in the process of development and growth under the policy guidance of adjusting and optimizing industrial structure, and accelerating in changing economic growth mode in China. Related market statistical report of merger, acquisition and reorganization shows that international M\&A market was active in 2009-2013. China M\&A market is prominent improved in both M\&A transaction quantity and M\&A transaction amount under the drive of global economic integration. 294 transactions were completed in domestic M\&A market deals in 2009 with M\&A amount of $\$ 33.147$ billion. 622 transactions were completed in domestic M\&A market deals in 2010 with M\&A amount of $\$ 34.803$ billion, 1157 transactions were completed in domestic M\&A market deals in 2011 with M\&A amount of $\$ 66.918$ billion, 991 transactions were completed in domestic M\&A market deals in 2012 with M\&A amount of $\$ 50.762$ billion; 1232 transactions were completed in domestic M\&A market deals in 2013 with M\&A amount of $\$ 93.203$ billion. Single payment mode can not meet reality demand with expansion of M\&A transaction scale, thereby hindering rapid development of China M\&A market.

\section{Main M\&A payment mode}

Enterprise M\&A payment modes in China include: cash payment, stock payment, debt assumption, free transfer, debt assumption, comprehensive securities pay, etc. Cash payment and stock payment are main payment mode from the perspective of final expression form of payment. In the paper, cash payment, stock payment and comprehensive securities payment are mainly introduced as three common payment modes.

\section{Cash payment}

Cash payment is one of favorable payment modes for both parties in M\&A. Appraisal of target company asset or equity value is only related in M\&A practice transaction. After transaction price is determined, transaction can be completely rapidly. Cash payment is clear and convenient. Cash payment is suitable for backdoor M\&A, malicious M\&A, M\&A with smaller amount and M\&A with equity separation and lower equity proportion of large shareholders. 
Cash payment has the following advantages: property rights are clear, program is convenient and evaluation is simple after M\&A; original equity structure is not changed; target enterprises can avoid the uncertain risks due to securities; beneficial signals of sufficient cash flow, stock undervaluation and stronger profit ability can be delivered to external market. Cash payment has the following disadvantages that cash payment will increase debt cost for the acquirer, pressure value of subsequent operation can be increased, thereby affecting normal operation; large-amount investment income will lead to massive cash inflow for target enterprise, higher corporate tax should be paid, thereby leading to higher tax burden. In addition, the value-added benefits will be lost if the enterprise has good development prospect and the target enterprise does not purchase stock after M\&A.

\section{Stock payment}

Stock payment mainly includes stock repurchase share swap, treasury share swap capital increase share swap and other modes. Stock repurchase share swap refers that the acquirer redeems stock in original shareholders of the company for replacing previous stock of target company, and the equity would not be diluted. Treasury share swap refers that the treasury share which is previously issued by the acquirer and repurchased subsequently is used for replacing original stock of the target company, and the equity will not be diluted. Capital increase share swap refers that new stocks are additionally issued to target company directionally in order to replace the original stock of the target company, and the equity of the acquirer will be diluted. The stock payment mode is applicable to transaction with larger M\&A scale. Stock payment has the following advantages: large amounts of cash outflow can be avoided, and excellent financial support can be provided for operation after M\&A. Strategic goals of the acquirer can be realized, and large-scale M\&A can be completed. Spot capital gain tax can be avoided, thereby delaying tax payment. Stock payment has the following disadvantages: the capital increase share swap is characterized by complex procedures and long M\&A duration, the best M\&A change may be lost, and original shareholder control right can be diluted. The target enterprise should bear operation risk after M\&A. Unbeneficial signal of over-valuating company stocks can be delivered to the market. If the equity of the target company is centralized, big shareholder's stake is higher, the acquirer equity is dispersed, large shareholder shareholding proportion is low, and the acquirer can suffer from the risk of reverse M\&A.

\section{Comprehensive securities payment mode}

Comprehensive securities payment refers that when the acquirer proposes tender offer to the target company, the payment consideration includes cash, stock, stock right, bonds and convertible shares. The acquirer can adopt various payment modes in order to meet demands of both parties. The payment mode can prevent control right transfer, and avoid fund limitation of subsequent operation. It has disadvantage that disadvantages of various modes can be comprehensive if payment modes are not properly matched. Comprehensive securities payment mode is an important payment mode, which is produced of financial tool innovation.

In a word, cash payment, stock payment and comprehensive securities payment modes have own disadvantages and advantages as shown in Table 1. M\&A modes suitable for own condition should be selected according to concrete condition in enterprise M\&A as shown in Table 1.

Table 1 Comparison table of three M\&A modes

\begin{tabular}{|c|c|c|c|}
\hline & Cash payment & Stock payment & $\begin{array}{c}\text { Comprehensive } \\
\text { securities payment }\end{array}$ \\
\hline $\begin{array}{c}\text { Probation } \\
\text { condition }\end{array}$ & $\begin{array}{c}\text { Small-scale M\&A } \\
\text { Hostile M\&A }\end{array}$ & $\begin{array}{c}\text { Large-scale M\&A, } \\
\text { Strategic M\&A }\end{array}$ & Large-scale M\&A \\
\hline Payment price & Higher & Lower & Moderate \\
\hline Income & $\begin{array}{c}\text { Target party income } \\
\text { determination: the income of } \\
\text { original shareholders of the } \\
\text { acquirer can not be diluted. }\end{array}$ & $\begin{array}{c}\text { Target party income is affected } \\
\text { by stock price: the income of } \\
\text { original shareholders of the } \\
\text { acquirer can be diluted. }\end{array}$ & Combination \\
\hline $\begin{array}{c}\text { Tax of target } \\
\text { enterprise }\end{array}$ & Spot tax payment & Delay in tax payment & Combination \\
\hline Financial risk & Higher & Lower & Moderate \\
\hline M\&A duration & Shorter & Longer & Longer \\
\hline
\end{tabular}




\section{Influence factors of enterprise M\&A payment mode selection}

M\&A payment mode selection is influenced by factors in many aspects, and the influencing factors mainly include the following aspects:

\section{Purpose of M\&A}

M\&A can make enterprise expand scale, obtain competition advantage and improve the ability to resist risks. M\&A has very large influence on enterprise medium and long-term development strategy. Therefore, M\&A purpose is an important factor that should be considered in the whole M\&A payment mode. M\&A mainly aims at achieving backdoor listing, strategy integration effect and financial synergy. Asset payment should be selected as payment mode to realize backdoor listing in enterprise M\&A mainly because the acquirer financing channel is limited, the business quality of shell resources is generally low, asset payment can improve asset quality of the acquirer, which is beneficial for improving overall profit level after backdoor mode is adopted. Enterprise financial integration effect can be realized. Cash payment is the optimal in M\&A payment. Governance structure of target enterprise has flaw due to improper management generally, thereby undervaluing enterprise value in the market. The acquirer can improve governance structure of target enterprise through own management and fund input, enterprise management can be strengthened, thereby obtaining potential value different of target enterprise. Stock payment is the best payment mode for realizing strategic synergy. Power cooperation between related parties, especially management level, between the acquirer and target company is required in integration process after M\&A. If the target company can enjoy right of sustained enterprise after M\&A, efficiency can be greatly improved in the integration process, which is beneficial for close cooperation of both parties, sharing future benefits of enterprise, and realizing win-win situation.

\section{Capital structure and financial situation}

Capital structure refers to composition and proportion condition of enterprise long-term capital, composition of equity capital and long-term debt as well as proportional relationship between the two aspects. When M\&A enterprise financial leverage ratio is higher, stock payment should be selected as M\&A payment mode. Capital structure can be optimized, and corporate debt level can be lowered. The acquirer can not produce increased cash flow pressure, thereby ensuring debt financing pressure of the company in the future. Leverage proportion can be suitably improved, and leverage effect can be exerted. Enterprise M\&A payment mode is affected by financial position of main M\&A enterprise. M\&A enterprise asset liquidity, future cash flow level, etc. can affect payment mode of enterprise M\&A. When M\&A payment mode is selected, the follows should be considered: whether there is enough cash ability or not, sufficient M\&A fund can be raised within stipulated period for completing M\&A transaction. After a large amount of fund is flowed inside, whether there is stable cash flow or not in the future, and capital turnover will be problem. If the above two factors can be satisfied during M\&A, cash payment mode should be adopted. If the above two factors can not be satisfied, cash payment mode can not be adopted, otherwise huge cash pressure can be caused to future operation of the enterprise. When enterprise fund liquidity is insufficient and future cash flow condition can not be determined, combined payment mode of cash payment and stock payment can be adopted during M\&A.

\section{Financing ability}

M\&A is an investment behavior. Financing is a source of enterprise investment fund. Enterprise financing mode has certain influence on enterprise M\&A payment mode. For example, cash payment can be realized through bank loan, stock and bond issuance as well as other financing modes. Stock payment can be realized through issuing common stock and preferred stock. Enterprise financing ability is affected by company scale, credit rating, cash flow condition and other factors. Financing channel can be derived from internal fund produced in enterprise daily business activities, which also can be derived from economic subject financing except the enterprise itself. In general, well-known large enterprises with ample cash flow and high credit rating can adopt cash payment mode more easily. Higher benefits can be obtained through appropriate financial leverage. Enterprises with listing status can obtain wider financing channel, it is easier to adopt stock payment mode for M\&A through capital platform. 


\section{Laws, regulations and tax policy}

China Securities Regulatory Commission revised Administrative Rules on Acquisition of Listed Company in 2006. Then, laws and regulations in the aspect of enterprise merger and reorganization can be constantly perfected in China. Opinions about Promoting Enterprise Merger and Reorganization were issued in 2010. Measures for Management of Material Assets Reorganization of Listed Companies were issued in 2011. These laws and regulations directly affect payment mode of enterprise M\&A transaction. Securities law is adopted as an example. Objective conditions and issuance procedures of issuing new shares in China re clearly regulated in securities law. Therefore, a part of enterprises are limited during selection of stock payment mode. Tax policy also can affect enterprise M\&A payment mode, tax solutions of different M\&A payment modes are great different in tax law. Enterprise M\&A aims at obtaining tax credits. Debts can be obtained during use of cash payment for acquirer, leverage role can be played, and interest can be listed before tax. Equity can be used for paying related cost, thereby reducing M\&A cost.

\section{Capital market maturity}

Capital market maturity directly affects the financing mode of capital for M\&A, thereby affecting M\&A payment mode. In European and American countries, capital market is more mature, therefore stock payment is more likely adopted in European and American market. China market is not mature enough, financing channel is narrower, financing tools are les, stock issuing cost is higher, procedures are trival, thereby restricting enterprise M\&A payment mode in China. Capital market is constantly developed with deepening of equity separation reform and system reform. Equity payment means are promoted gradually. In the future, when enterprises select equity payment, payment mode capable of promoting M\&A transaction can be selected according to economic development condition and capital market maturity.

\section{Summary and recommendations}

Enterprise M\&A payment modes mainly include cash payment, stock payment and comprehensive securities payment mode. In the paper, it is believed that main factors affecting enterprise M\&A payment mode selection include the follows: M\&A purposes; capital structure and financial situation; financing ability; laws, regulations and tax policy; capital market maturity according to research and analysis. In the paper, it is believed that M\&A enterprises should combine with actual situation, and fully consider influence factors of many aspects based on enterprise actual condition, thereby selecting the best payment mode.

In M\&A, the target enterprise should strive to adopt cash payment mode to ensure that the company shareholders can realize wealth maximization, future difficulties in enterprise operation can be effectively avoided after M\&A. In addition, when the target enterprise selects payment modes, influence of synergies effect, tax policy and other factors after M\&A should be fully considered. When the acquirer selects payment mode, other factors should be comprehensively considered based on consideration of M\&A purpose. The acquirer had better select asset replacement mode for the purpose of back-door listing, thereby implanting own high-quality business; cash payment mode is generally adopted in M\&A for the purpose of financial restructuring. Stock value of the company should be considered for the purpose of strategic restructuring. If stock value of the company is overvalued, equity payment mode should be adopted. If the stock value of the company is undervalued, cash payment mode should be adopted, and beneficial signals can be delivered to the market.

\section{References}

[1] Wang Dan, Liu Weilin. Overview of influencing factors of payment mode in enterprise M\&A [J]. Business Manager. 2012 (5): 19-21.

[2] Teng Jianhui. Enterprise overseas technology M\&A issues and countermeasures. [J]. Small and Medium-sized Enterprise Management and Technology (third issue), 2012 (6): 69-71. 
[3] Jia Bei, Gu Dan. Analysis on enterprise M\&A payment mode. [J] Business Accounting. 2012 (16): $124-126$.

[4] Li Wei. Selection of enterprise M\&A payment mode and risk aversion. [J]. Business Accounting. 2012 (15): 77-79.

[5] Wang Guipu, Yu Leiming, Kong Yejung. Empirical analysis on influence of cash payment and stock payment selection on acquirer performance influence. [J]. Journal of Agricultural Bank of China Wuhan Training College. 2012 (3): 154-156.

[6] Zhang Zhihui. Analysis on M\&A payment mode decision-making based on cooperative value. [J]. Modern Commercial Industry. 2012 (5): 99-102.

[7] Duan Kefu, Wang Wei. Thinking on enterprise M\&A payment mode selection. [J]. China Township Enterprise Accounting. 2012 (02): 37-38. 